\title{
DE LA NOVELLA AL ENTREMÉS PASANDO \\ POR LA NOVELA CORTA: REESCRITURAS DEL CUENTO \\ LA GARA DELLE TRE MOGLI DEL CIECO DI FERRARA
}

\author{
ILARIA RESTA \\ Università del Salento \\ ilaria.resta@unisalento.it
}

L a actividad investigadora que, desde el siglo xIx, se ha encaminado hacia el examen de la vinculación de la novella con el resto de la literatura española durante la Edad de Oro se ha revelado como una cantera de reflexiones estimulantes por la complejidad de este fenómeno de contaminación. La indagación de los fundamentos y las modalidades que atienden a la circulación de estos textos en España, de hecho, se integra en un panorama heterogéneo que no se amolda al ámbito meramente filológico, puesto que comprende escenarios abiertos también a dinámicas de carácter sociocultural.

Por otra parte, ha pasado casi del todo desapercibido otro aspecto interesante vinculado con la recepción de la novelística italiana en España: en general, al examinar este fenómeno, la crítica ha restringido el campo de investigación a la profundización en las colecciones de los novellieri propiamente dichos, prescindiendo de otros escritores que, especialmente durante el XvI, se acercan a la narración breve fusionándola con otras tipologías textuales. Según se verá, no solo los cuentos de los italianos más afamados en la prosa breve (Boccaccio ante todo, pero también Bandello, Straparola, Giraldi Cinzio, Masuccio Salernitano) se convirtieron en material moldeable, sino que incluso los relatos de autores que, sin ser definidos como novellieri, de alguna manera se han arrimado al arte del novellare, pasan a integrar esa mina de temas y motivos novelísticos a la que acuden con frecuencia los españoles. En especial, lo que trataré de demostrar es cómo un motivo cuentístico incluido en el poema caballeresco Mambriano de Francesco, apodado el 'Cieco di Ferrara', se transmitió mediante un triple proceso de reescritura, primero en Italia, en un cuento del veneciano Orazio Celio Malespini, y sucesivamente en la literatura española: en una novela corta de Tirso de Molina y en un 
entremés de Francisco de Castro. Se trata de una transformación sumamente interesante al afectar, a la vez, al ámbito narrativo y dramático; sin contar con que las modalidades que atienden a la trasmisión de la historia se desarrollan siguiendo el mecanismo de las cajas chinas.

En este sentido, cada obra que examinaré no solo se convierte en un catalizador para la sucesiva difusión del relato de las tres mujeres burladoras, sino que favorece la resemantización del mismo, al incluir elementos añadidos que modifican parcialmente el tema; elementos que se transmiten en el texto sucesivo y contribuyen a identificar una vinculación directa entre la novella del Cieco y la prosificación de Malespini, entre el cuento del veneciano y una novela corta incluida en los Cigarrales de Toledo y, finalmente, entre el relato de Tirso de Molina y el entremés La burla de la sortija.

En pleno Renacimiento la novella consigue desvincularse del modelo de difusión al que se vio sometida desde sus orígenes - circulando exclusivamente como parte integrante de las colecciones de cuentos (con o sin marco), o en forma de sueltas, las llamadas novelle spicciolate-, pasando a contagiar otros géneros entre los que priman la tratadística, la epistolografía y el poema caballeresco. En época humanística, en definitiva, la novella abre una puerta a la experimentación, superando la noción de género como compartimento estanco para complementarse con modalidades literarias diversas y con finalidades divergentes. Es bien conocida la importancia de la narración breve en el Quinientos, época en la que se asiste a una estandarización de la misma, en relación con la definición de su paradigma y sus principios estructurales, como consecuencia de unas coyunturas de carácter sociocultural. Basta recordar, a este propósito, que el cuento breve en Italia adquiere el estatus de literatura de consumo, propagándose en forma oral y escrita en todos los estamentos de la sociedad. La relevancia de este fenómeno literario, además, se consolida también gracias a un cambio de tendencia por parte de los ambientes culturales: en un primer momento menospreciada, la novella empieza a cautivar el interés de los literatos. Bembo en las Prose della volgar lingua (1525) ensalza la prosa boccacciana, definiéndola como un modelo estilístico y lingüístico; asimismo, en tratados de cortesanía como Il Cortegiano (1528) de Castiglione o Il Galateo (1558) de Della Casa, así como en los tratados de retórica, entre los que merece la pena recordar la Lezione sopra il comporre delle novelle de Bonciani (1574), se asiste a un primer intento de dignificación y codificación del género. De igual forma, el Xvi es el momento en que la novella va contaminando otros espacios literarios y principia un diálogo prolífico con otras fórmulas de escritura.

Un caso emblemático es el de Il Cortegiano. Castiglione se complace en intercalar de vez en cuando cuentos y facecias que marcan una de las prácticas de buena conducta del cortesano en las conversaciones: el arte de novelar. En el segundo libro se da una muestra de facecias y relatos chistosos que sirven para ejemplificar 
una de las habilidades del hombre cortesano: manifestar un punto de gracia, deleitando a los oyentes en las reuniones, aunque siempre amparándose en la «ragionevol misura» (Castiglione 1960: 47). Si para Castiglione la inclusión de relatos breves posee una connotación instrumental y didáctica que sigue de cerca el modelo del exemplum, hay que subrayar que en otros casos la presencia de la novella en géneros diferentes se asocia a una finalidad estética. La entidad monolítica e independiente de los relatos breves hace que estos se incorporen dentro de otras obras sin necesidad de mantener una continuidad argumental con las mismas, ya que la incrustación de las historias solo pretende darle varietas a la ficción principal que, por ende, no sufre ninguna alteración. Es lo que se deduce especialmente del poema caballeresco: en los de Boiardo y Ariosto es posible apreciar esta variación genérica que fragmenta la acción principal, proporcionando un descanso lúdico y una pluralidad de tonos (Carapezza 2011: 12).

Entre los cultivadores de estas fórmulas mixtas en el género caballeresco hallamos la figura de Francesco, el 'Ciego de Ferrara', autor que no cuenta aún con un perfil crítico muy definido entre los poetas italianos de finales del siglo Xv. Debe su fama principalmente al Mambriano, una obra publicada póstuma que para la crítica se ha vuelto una fuente imprescindible para extraer informaciones sobre el autor, aunque no se ha revelado suficiente para aclarar algunos puntos que quedan todavía oscuros sobre su vida y trayectoria artística.

El Mambriano es un poema caballeresco en 45 cantos que cimienta su argumento en el ciclo carolingio, entroncado con la epopeya de Rinaldo: publicado por primera vez en Ferrara en 1509 por Mazzocco, la obra tuvo una gran acogida, manifiesta en la cantidad de reediciones que se publicaron en el XVI (Rua 1888: 21). Debe su título al nombre de uno de los protagonistas que desencadena la acción, el moro Mambriano, que clama venganza por el asesinato de su tío Mambrino a manos de Rinaldo. Una dimensión peculiar del Mambriano es la intercalación de cuentos breves en forma poética que enraízan con la tradición cuentística literaria y folklórica: el Ciego incluye siete novelle en que el autor reelabora temas y motivos célebres de la tradición cuentística. A diferencia de otras obras como L'Orlando innamorato, o bien L'Orlando furioso, en las cuales la incrustación de estos fragmentos graciosos no mengua la relevancia del tema medular, en el Mambriano los cuentos han venido ofuscando el resto de la fictio, al punto de volverse a lo largo de los siglos más populares que los avatares del héroe carolingio relatados en la obra del Ciego. Consecuencia última de esta fama será la publicación de las novelle por separado y su circulación en la península italiana ya a partir del siglo xvi. Forma parte de este grupo de relatos la novella de las tres mujeres y el anillo, una de las más populares del Mambriano, que hunde sus raíces en la tradición francesa. El motivo, de hecho, se desarrolla en Europa a través del fabliau titulado Les trois dames qui trouvèrent l'anneau, para luego ser reelaborado en una serie 
de versiones alternativas. Bédier, a este propósito, ha proporcionado una lista de todas las versiones literarias y populares recogidas por él, Liebrecht y Rua, y que se incluyen en un lapso de tiempo que va desde las primeras del siglo XIII hasta el XVIII (Bédier 1982: 267-268). Se trata de adaptaciones que transforman en parte la fábula y la tipología de las burlas, aunque por otro lado siguen manteniendo un fondo común que las pone en conexión entre sí.

En el poema del Ciego tres mujeres se disputan un anillo, que según el dictamen del profeta Merlino — al que las tres escogen como juez de la pendencia-, conseguirá la que urda la burla mejor a costa de su marido: la primera confunde al esposo haciéndole creer que su casa se ha convertido de repente en una venta; la segunda logra arrancarle un diente sano; la tercera persuade al cónyuge de que es un fraile de un convento. Los engaños se emparentan solo parcialmente con la dinámica burlesca que esboza originariamente el fabliau, con una semejanza limitada a la última burla; por lo demás, los episodios proceden en cambio del caudal novelístico de ascendencia italiana. Resulta paradigmático el caso de la segunda mujer, que al final conseguirá el anillo, cuya historia deriva de forma muy evidente del cuento decameroniano VII, 9 (es una de las pruebas a la que Lidia somete al marido estulto para demostrarle su lealtad al amante Pirro). En definitiva, es probable que el Ciego de Ferrara recuperara para su historia no directamente el fabliau, sino alguna que otra adaptación transmitida oralmente, reciclando solo la estructura profunda de la misma — es decir, tres mujeres que por una joya urden tres engaños a costa de sus maridos- pero luego introduciendo una serie de variantes que afectan tanto a la fábula como a la intriga.

De todas las novelle que se hallan en el Mambriano y que se difunden escindidas del resto del poema, esta sin duda es una de las más renombradas: a partir de la primera edición, que sale en Florencia en 1558, la Historia nova di tre donne che ognuna fece una beffa al marito per guadagnare un anello, han sido catalogadas nueve versiones que circulan en Italia hasta el siglo XIX (Rua 1888: 110). Se trata de ediciones spicciolate que omiten el autor, lo que, por ende, ha contribuido a que el texto se divulgase como parte integrante de la tradición anónima de índole folclórica. Solo a principios del xx, gracias a la labor investigadora de Rajna, se ha podido rescatar la identidad del escritor, atribuyéndole nuevamente al Ciego la autoría del cuento (Rajna 1878: 23).

Aparte de la difusión en forma desglosada, el cuento se reintegra de forma completa en una colección de cuentos breves, el Ducento novelle, que Orazio Celio Malespini edita en Venecia en 1609 con el tipógrafo Al Segno dell’Italia. Figura ambigua y controvertida del panorama literario, más que al espíritu humanista de la imitatio, Malespini se acoge a una práctica de reproducción-calco de otras obras, cayendo en lo que hoy definiríamos como plagio (Saltini 1894: 3580). En muchos de los cuentos que integran su colección se advierte claramente 
la impronta de la tradición anterior, llegando a remozar, o hasta calcar, motivos y relatos íntegros procedentes de la literatura extranjera e italiana: reproduce 96 textos de las Cent nouvelles nouvelles; 4 episodios de la Diana de Jorge de Montemayor; una novella de Anton Francesco Doni y 4 del Ciego de Ferrara. De este último procede el cuento 95 de la Parte II. Más que de adaptación, convendría hablar de prosificación, ya que Malespini reproduce servilmente el texto, limitándose a diferenciarlo en algunos detalles; leves diferenciaciones que, en algunos casos, no provocan ningún tipo de fricción con el cuento del Ciego (por ejemplo, la modificación del apellido del marido en la tercera burla: Colombino > Cherubino; o en la primera chanza, la variación del nombre del especiero al que tiene que acudir el esposo estulto: special del Giglio > speciaria del Moro). En estos casos nos hallamos ante modificaciones insustanciales, que no aportan nada inédito al cuento.

En otras ocasiones, en cambio, la intromisión de nuevos elementos argumentales promueve una falta de coherencia lógica en el desarrollo de la acción en el momento en que los pormenores añadidos colisionan con el original. Al introducir el relato, Malespini habla de una gemma que se disputan las esposas: esta pequeña variante, sin embargo, solo viene incluyéndose en la rúbrica que precede al texto, ya que en el cuento sigue aludiendo al mismo objeto presente en la versión lírica del Ciego: el anillo. Otro ejemplo de incoherencia textual se vislumbra en la tercera burla, la del marido al que se le hace creer que es un monje. En el Mambriano el éxito del engaño se ve condicionado por la connivencia de un fraile, que, por lo que nos sugiere subrepticiamente el autor, es el amante de la mujer: «Ebbe ricorso al suo messer l'abate, / il qual, già molto esperto nel viaggio, / con due monaci entrò per vie celate» (Bello 1926: 225). Malespini, en cambio, suprime el fragmento original convirtiendo al fraile-amante en un monje hermano de la protagonista. Es posible que tal decisión del novelliere veneciano estuviese vinculada con la necesidad de no tener problemas con la censura inquisitorial. Hace falta recordar que el Mambriano se publica a principios del xvI mientras que el Ducento novelle sale por primera vez de los talleres venecianos un siglo más tarde, cuando ya las consecuencias del Concilio de Trento habían ocasionado una convulsión sociocultural significativa. En 1559, con el primer Índice Romano, la Iglesia Católica se lanza hacia un férreo control de la cultura y difusión de determinadas obras consideradas contrarias a la fe, las costumbres y la moral. Como consecuencia, tanto en el índice de 1559 como en el sucesivo de 1564 se incluyen el Decamerón de Boccaccio, el Novellino de Masuccio Salernitano y el Liber facetiarum de Poggio Bracciolini. La vigilancia puesta en el mercado del libro y en la divulgación de determinadas obras, especialmente las vinculadas con el género novelístico, produce entonces una mayor cautela por parte de los novellieri y de los editores a la hora de poner en circulación estos relatos. 
Volviendo a Malespini, por un lado el veneciano quita toda referencia antieclesiástica; sin embargo, no se contenta con alterar el tipo de relación entre la protagonista y el religioso. De ahí que decida añadir la referencia a los celos extremados del marido como pretexto para justificar la voluntad de un eclesiástico de hacerse cómplice de la burla. A nivel argumental se trata de una variación interesante que hubiera podido darle un camino diferente a la historia primordial; Malespini, en cambio, es incapaz de desvincularse de su apego por el plagio «e continua a copiare fedelmente il Cieco, senza darsi alcun pensiero del nuovo aspetto assunto dalla novella» (Rua 1888: 114).

Quince años después de la publicación de la colección de Malespini, y ya en España, Tirso de Molina edita los Cigarrales de Toledo. En el prólogo a la obra es tajante al declarar su desapego respecto a la tradición italiana, hablando de unas futuras «doce Novelas, ni hurtadas a las Toscanas, ni ensartadas una tras otra como procesión de disciplinantes» (Molina 1968: 13). Sin embargo, más que una programática intención de absoluta originalidad por lo que toca a la materia tratada, la afirmación de Tirso parece expresar una voluntad de adecuarse a una retórica que marca la senda de los novelistas españoles en esa época. Desde la célebre declaración de Cervantes, quien sostenía ser el primero que había «novelado en lengua castellana» (Cervantes 2003: 52), no pocos escritores se beneficiaron de las partes prologales para insistir en la novedad de esta modalidad narrativa y tomar distancia o renegar del cuento breve italiano que, sin duda, en un primer momento había sido un modelo de referencia y una provechosa mina de inspiración argumental. En su prólogo, Tirso nos advierte que no hurta sus novelas a las toscanas; no obstante, parece ser que se acoge a la tradición italiana (si no a la toscana, por lo menos a la veneciana) para la novela incluida en el Libro $\mathrm{V}$, donde hallamos la historia de las tres mujeres y el anillo: se trata de una versión que con toda probabilidad, según ha señalado Rua, procede directamente de la de Malespini (Rua 1888: 110-115).

No tengo constancia de que Malespini fuera un novelliere afamado en la península ibérica, y tampoco he podido encontrar elementos que indicaran la posibilidad de que el Ducento novelle circulara en la península ibérica, pese a que Giambattista Marchesi declarase en 1897 que «l'opera del Malespini fu tradotta in ispagnuolo nel 1612» (Marchesi 1897: 27). Faltan los fundamentos para sostener esta declaración que, con mucha probabilidad, fue el producto de un malentendido, puesto que Marchesi, a su vez, remite a una nota de Rua en la que se habla de la «traduzione del Malespini», pero el crítico italiano no se refiere a la traducción del Ducento novelle, sino a una versión italiana del Jardín de flores curiosas de Torquemada, que realiza Malespini y Pietro Bertano edita en Venecia aquel año. Sin embargo, no es descartable que Tirso haya podido conocer y manejar esta colección, quizá como consecuencia de la vinculación de Malespini con España: el veneciano, de hecho, participó en la guerra de Flandes junto al bando español y 
sucesivamente también estuvo relacionado con la corte española durante su estancia milanesa.

Desconocemos, por lo tanto, de qué forma la colección de Malespini (o parte) pudo llegar a manos del mercedario; lo que sí es cierto es que, al confrontar los textos, existen varias concordancias internas entre la novela de Tirso y la versión de Malespini que dejan sospechar la posibilidad de que se haya producido una traslación de material de una obra a otra. Ante todo, la referencia a la gemma que el veneciano introduce en la rúbrica mantiene una similitud con el «anillo con diamante» que encuentran en un jardín las tres mujeres. Pero los puntos de concordancia más concluyentes se vislumbran en la tercera burla, la del marido al que le hacen creer que es un monje. Según he subrayado anteriormente, Malespini modifica el original del Ciego e introduce la figura del fraile hermano, eludiendo de esta forma el peligro de la referencia a la actitud libidinosa de los eclesiásticos que se infiere de la versión del Mambriano. Asimismo, se mantiene la alusión a los celos desmesurados del cónyuge, a los que apela la mujer para persuadir al fraile a que la auxilie para mejorar el carácter del marido:

Acababa de llegar a Madrid un religioso, hermano suyo, por prelado de uno de los monasterios [...]. Se le había quejado de la mala vida que sus impertinentes sospechas la daban [...]. Estaba informado el prudente religioso de los vecinos y amigos del mal acondicionado viejo, de la razón que su hermana tenía de aborrecerle y vivir desconsolada (Molina 1994: 538).

Dato a credere la terza moglie ad un suo fratello, che era priore di un monasterio de' frati, il bianco per il nero per interesse di suo marito per risanarlo dal grave male della gelosia, per la quale ella menava una amarissima e dolorosissima vita (Malespini 1609: 309).

Por otra parte Tirso, a diferencia de Malespini, consigue aprovechar la variación del tema, incluyendo en el desarrollo de la intriga una serie de novedades que dinamizan y diversifican la acción. Por ejemplo, agrega en el epílogo el motivo de la conversión del celoso que se produce a raíz de una mediación supuestamente divina en que se avisan las huellas de la novella de Ferondo del Decamerón (III, 8):

Volviéronle a disciplinar y meter en el cepo, donde después que purgó más de otro mes los malos días que había dado a su mujer, al cabo dellos y a la media noche le despertó una voz desde el tejado que estaba sobre la prisión, y decía en tono triste y sonoroso:

Hipólita está inocente de tus maliciosos celos, y así te han hecho los Cielos 
de ese cepo penitente.

Por necio e impertinente, en ti su venganza funda el que te ha dado esa tunda; por eso, si sales fuera, escarmienta en la primera, y no aguardes la segunda.

Repitió esto tres veces la fúnebre voz, y él, puestas las manos llorando, con la mayor devoción que pudo, respondió: «¡Oráculo divino o humano, quienquiera que seas, sácame de aquí; que yo prometo verdadera enmienda!» (Molina 1994: 554).

Estos detalles indudablemente reflejan una cercanía del cuento de Malespini a la novela corta de Tirso de Molina, pero, por otra parte, conviene señalar una diferente actitud del mercedario respecto a la del novelliere veneciano. Mientras este, según ya he señalado, calca la historia del Ciego de Ferrara, Tirso diferencia el orden de las burlas y, sobre todo, modifica la mecánica de una de las tres beffe. De modo que en el Ciego de Ferrara y Malespini tenemos primero la burla de la venta (al primer marido le hacen creer que su casa se ha trocado en una posada); la segunda es la burla de ascendencia decameroniana (la mujer consigue extraerle con un engaño una muela sana al marido); y la tercera es la del marido al que le hacen creer que es un fraile.

En los Cigarrales, el episodio de la venta se corresponde con la chanza que urde la segunda mujer, mientras que el fragmento de la extracción del diente bueno desaparece y se sustituye con otro motivo de raíz folclórica y literaria: el del hombre al que se le hace creer que ha muerto. Es fácil detectar en algunas situaciones que la víctima de la chanza acusa las huellas de ciertos episodios procedentes de diferentes novelle del Decamerón protagonizadas por el estulto Calandrino: considérese a este propósito, la conexión con la novella VIII, 3, donde el protagonista es inducido a creer que se ha hecho invisible y los demás personajes hablan de él en su presencia fingiendo no verle, situación que se recupera en Tirso en el momento en que el marido tonto escucha por la calle a sus amigos hablar de él como si hubiese fallecido. La misma vinculación se vislumbra, además, en el motivo del hombre persuadido de estar enfermo presente en el cuento IX, 3 del Decamerón (reelaborado de forma original por Bracciolini en la facecia CCLXVII). Rua, por su parte, menciona una variante siciliana del cuento del Ciego de Ferrara, Li tri cumpari, recogida por Pitré, en el que en un mismo episodio se combinan las burlas del monje con la del hombre fingidamente muerto (Rua 1888: 110-111). Es cierto que esta versión no tiene nada que ver con la española, aunque demuestra que en aquella época la novella del Mambriano circulaba en numerosas adaptaciones orales que contemplaban la diversificación de las burlas, a veces añadiendo 
episodios procedentes del folklore, y a veces sacándolos del Decamerón, especialmente de las múltiples beffe que aparecen en la novella VII, 9.

Por otra parte, hay que incidir en que en la península ibérica ya circulaban otras versiones orales del mismo motivo — no vinculadas con la adaptación del Mambriano - en las que aparece el episodio del hombre fingidamente muerto. Se encuentran rastros en muchísimos entremeses del xvII, pero especialmente en uno de principios del XviII, el Entremés del muerto antes de morir, incluido en una colección manuscrita a nombre de Antonio Abad Velasco. A diferencia del cuento de origen literario, esta pieza plantea una disputa entre tres hombres por una mujer: la adúltera establece que se entregará a quien burle mejor a su marido, que, por culpa de su consorte, se verá despojado de su dinero, sus capones, su ropa, se le cortará el pelo y, finalmente, le harán creer que ha fallecido.

En el caso de Tirso, entonces, es probable que su novela corta sea el resultado de una contaminatio entre literatura y tradición oral: de ahí que a partir de la versión incluida en la colección de Malespini, sobre cuya posesión todavía no queda desvelado el enigma, el mercedario haya decidido modificar la segunda burla, sustituyéndola con otro episodio sacado con toda probabilidad del folclore local y que, narrativa y estructuralmente, homogeneizara con las otras dos chanzas.

Para completar este excursus sobre las reescrituras del cuento La gara delle tre mogli, hace falta trabar el último eslabón de este recorrido que nos lleva al ámbito teatral del Siglo de Oro y, más concretamente, al género entremesil con La burla de la sortija. Aparecida por primera vez en 1742 en el tomo I del Festejo cómico de Francisco de Castro, la pieza teatral reintegra de forma casi completa el motivo de las tres mujeres que se disputan una joya. Se atisban en este texto unos cuantos elementos de procedencia tirsiana, aunque por otra parte el entremesista no renuncie a la intromisión de fragmentos originales, optando por una aclimatación del asunto a la dinámica performativa del entremés, que se manifiesta en diferentes niveles:

1. Estereotipización de los personajes a través de la sustitución de los protagonistas de la novela por figuras mecanizadas de los entremeses (barbero, licenciado, soldado, vejete);

2. Condensación de la materia novelística. La brevedad del género impide que se representen en la escena las tres burlas que, por tanto, se reducen a la escenificación de una sola (la de la casa trocada en una venta), mientras que las otras dos se pasan de puntillas mediante una alusión fugaz de Cristina, la mujer que urde la chanza a costa del vejete;

3. Inclusión de elementos colaterales y ajenos a la historia y que entroncan con las convenciones del género. Estamos ante unos fragmentos cómicos reproducidos en entremeses anteriores y que encajan en la ficción pero sin añadirle nada al argumento, pues poseen una mera función lúdica: véanse 
a este propósito la riña estrafalaria entre el Barbero y el Licenciado en el íncipit de la pieza; la escena de la competición entre ambos y el Soldado por el abrazo a Cristina; o bien el episodio del Vejete que va tocando de noche a la casa de sus vecinos, preguntándoles por su vivienda. Se trata evidentemente de situaciones en que la risa es el resultado de una comicidad elemental, física, que deriva de los movimientos de los actores y las súbitas salidas y entradas de las figuras en la escena.

Al comparar el entremés con la novela de Tirso, por otra parte, asoman una serie de elementos afines sobre los que conviene detenerse un momento, ya que son la evidencia del alto grado de intertextualidad que los textos mantienen entre sí. En la primera escena interviene Cristina para declarar su propósito a sus tres pretendientes, aludiendo al diamante que ella y sus dos amigas han hallado. Según he señalado, la alusión a la piedra preciosa es una variante introducida por Malespini frente a la versión del Ciego, aunque en el caso de la novela española se añade el detalle del diamante. Castro recupera en el entremés esa misma referencia junto al contexto socio-espacial del hallazgo:

CRISTINA Una tarde, saliendo el rey a Atocha, yo y otras dos amigas a ver fuimos a nuestro gran monarca, y descubrimos una sortija con diamantes nuevos, porque son, no es mentira, como huevos (Castro 1742: 113).

Concertaron para el día de San Blas, que se acercaba, salir al sol y a ver al rey que se decía iba a Nuestra Señora de Atocha aquella tarde. [...] Cumpliose el plazo y [...], reparando en una cosa que relucía en un montoncillo de basura a un rincón della, dijese la mujer del celoso:

— ¡Válgame Dios! ¿Qué será aquello que brilla tanto? [...] Acudió solícita a examinar lo que era la pintora, y sacó en la mano una sortija de un diamante hermoso (Molina 1994: 527).

De igual forma, se rescata la identidad social del árbitro de la contienda que, a diferencia de las versiones italianas en las que se alude al profeta Merlino, tanto en la versión de Tirso como en el entremés es de noble estirpe (un conde en un caso, un vizconde en el otro). Además, el nivel de adhesión al texto prosístico por parte de Castro es tal que hasta reproduce ciertas expresiones lexicales que se hallan en los Cigarrales. Al aludir a la tipología de la prueba a la que las tres mujeres someterán a sus maridos para conseguir la joya —esto es, cuál de ellas los burla mejor-, el mercedario introduce un cauteloso comentario moralizante que sirve para reglamentar las beffe, haciendo hincapié en que el engaño no perjudique al 
honor del esposo. En ninguna de las versiones italianas se halla este comentario, que, en cambio, sí aparece en el entremés de Castro:

CRISTINA. Un vizconde, vecino de mi casa, en un coche simón por allí pasa; conociome y me dijo que qué había. Contele el caso y dio su señoría un arbitrio, que fue que la que hiciera mayor burla a su esposo consiguiera la sortija, que fuese limpiamente sin pasar de su línea lo decente (Castro 1742: 114).

—Allí está paseándose con otros caballeros el conde mi vecino. Comprometamos en él, llamándole a parte nuestras diferencias.

[...] Era el conde de sutil entendimiento; y con la cortedad del término que le daban, respondió:

- [...] Sentencio y fallo que cada cual de vosotras dentro del término de mes y medio haga una burla a su marido — como no toque en su honra—, y a la que en ella se mostrare más ingeniosa, se le entregará el diamante (Molina 1994: 528).

Asimismo, cabe mencionar que Cristina alude a las burlas que sus dos amigas ya habían prevenido a sus maridos y que entroncan exactamente con las que propone Tirso, la del fraile y la del muerto, reemplazando esta última la beffa de la extracción del diente presente en el Ciego de Ferrara y en Malespini:

CRISTINA. Las otras dos sus chascos han logrado

y cada una a su esposo se le ha dado, haciéndoles creer las dos de cierto una al suyo que es fraile, otra que es muerto (Castro 1742: 114).

Pasando ahora a la segunda secuencia de la pieza, escenifica la burla a través de un mecanismo que es en todo igual al de Tirso: por la noche, la mujer finge un malestar improvisado, obligando al marido a que salga en busca de un médico. A la vuelta, el estulto se sorprende al notar que su casa se ha trocado en una venta. Incluso en esta segunda escena el entremés se mantiene del todo fiel a la novela corta, de la que recupera hasta los detalles más nimios:

- la identidad social del marido (en ambos casos es un pintor que está realizando un retablo);

- la localización en Lavapiés de la casa de los cónyuges;

- la referencia a la situación meteorológica que amplifica la comicidad del episodio (igual que en la novela, Cristina envía al Vejete a casa del médico 
pese al mal tiempo, de forma que el hombre volverá «remojado» a su vivienda);

- la descripción del momento en que la mujer, gracias a la ayuda de unos cómplices, convierte su casa en una posada;

- la decisión del vejete de irse a casa de un amigo.

La semejanza a la hora de reproducir ciertos pasajes de la novela se puede comprobar en el episodio de la vivienda transformada en una venta durante la momentánea ausencia del vejete. Esta congruencia es especialmente evidente en la larga y detallada acotación que acompaña a la escena:

Vanse y salen todos los que dicen los versos y los peones luego con la puerta.

CRISTINA ¡Ah! ¡Caballeros!

Todos ¿Qué hay?

CRISTINA ¿¿No me han oído?

VizConde Sí, cierto. Y por mi fe que lo has fingido de suerte que me vi casi engañado.

SOLDADO ¿Cómo vendrá el pobrete?

Cristina Remojado.

[...]

Sacan dos hombres la puerta de igual a la otra, que habrá puesta al lado izquierdo y será de distinta hechura. Entran por un lado y salen por otro: quitan la puerta que estará con unas almellas de encaje, y la otra que es al propio igual se encaja en las almellas, y ponen encima una tablilla que diga 'Casa de Posadas' y un farol, con su luz, encima de la puerta (Castro 1742: 117-118).

Que entre tanto que él se va echando en remojo, volveré yo a la enferma de bellaquería y no de males de estómago; la cual, en viendo fuera de casa a su buscón marido, llamó a su hermano, que estaba escondido en la cueva con otros dos amigos, y en un instante quitaron la puerta antigua de la calle y pusieron la nueva, que ya tenía su cerradura y aldaba y se había ajustado a los quicios y medido de suerte que, sin ruido, se asentó como de molde. Encima della, en el frontispicio, clavaron una tabla mediana, y escrito en campo blanco: Casa de Posadas (Molina 1994: 540).

No obstante, según he avisado, el entremesista no renuncia a incluir algunos elementos típicamente teatrales que le dan más dinamismo a la historia y un tono de farsa: de ahí que se elimine el diálogo estático entre el marido y el ventero, sustituyéndolo por un fragmento cómico, que se repite con leves diferencias en el que el vejete llama a sus vecinas preguntando por su vivienda. Indudablemente, la mecanización de una misma situación es una de las estratagemas que se utilizan en los entremeses en general y en esta pieza en particular para otorgarle comicidad a 
la acción a través de una combinación del elemento lingüístico —en la reincidencia de idénticas locuciones que usa el Vejete — con el juego escénico que se da en la alternancia breve y rápida de los personajes en la escena -las vecinas que responden al vejete- - . Esta amalgama de episodios y expresiones verbales procedentes de Tirso, con una variación argumental de ascendencia entremesil, se mantiene intacta en la tercera y última escena de la pieza. Por un lado, Castro sigue el desarrollo de la novela, y, como consecuencia, de la novella italiana, al agregar el episodio de la cólera simulada de la mujer por la ausencia nocturna del marido. Por otra parte, el entremés prosigue por un camino diferente debido a dos motivaciones: una de coherencia argumental y otra de coherencia genérica. Respecto a la primera, conviene recordar que en los Cigarrales el conde acaba repartiendo el premio entre las tres mujeres. En el entremés, en cambio, se escenifica una sola chanza: Cristina es la protagonista absoluta, mientras que las otras esposas solo se nombran al principio, y nunca aparecen en escena. Por tanto, hubiera resultado cuando menos incoherente a nivel argumental y representativo un final afín al de la obra en prosa, con una repartición del premio entre una figura central de la acción y otros dos personajes que no se integran en la fictio de forma activa. La segunda diferencia, en cambio, se produce por un acercamiento a la práctica del género entremesil marcado por unos finales estandarizados en los que se celebran con bailes y cantos la armonía recobrada. De ahí que en la conclusión Cristina le revele a su esposo su estratagema, a diferencia de la novela de Tirso, en la que el marido queda mortificado por la reprimenda de su mujer y termina sin darse cuenta de haber sido víctima de un engaño.

A modo de reflexión final, hemos visto que en la transmisión del motivo a partir del Mambriano hasta el entremés de Castro, el relato se conforma, en su última etapa, como el resultado de un triple filtro, readaptándose continuamente en el pasaje a través de literaturas y géneros distintos. No deja de suscitar curiosidad el hecho de que a lo largo de este camino literario el cuento adquiera estilos divergentes, pasando de la forma lírica a la prosa, para terminar por expresarse nuevamente en verso. Es cierto, además, que en este trasvase la forma primitiva de la historia se modifica, se suprimen ciertos elementos de la intriga para reemplazarlos con otros más conformes al propósito del escritor y a las peculiaridades de la tipología textual en la que se insertan. Esta variabilidad de contenido, que solo se esboza en Malespini, alcanza madurez plena en la versión española de Tirso y, sucesivamente, en la reelaboración entremesil de Castro. A propósito de este último, el entremesista desatiende la propuesta italiana del Ciego (o bien la de Malespini), ciñéndose directamente al relato de los Cigarrales, si bien le añada su dosis de alteración en el momento en que la novela se readapta según el estilo convencional del teatro breve mediante una serie de expedientes que dinamizan el conjunto y le confieren un tono de farsa. 
Recibido: 15/09/2014

Aceptado: 30/10/2014

OBRAS CITADAS

Abad Velasco, Antonio (s. XVIII). Colección de comedias, entremeses, poesías y otros varios asuntos, h. 176-188 [BNE: Mss/14770].

Asensio, Eugenio (1971). Itinerario del entremés. Desde Lope de Rueda a Quiñones de Benavente con cinco entremeses de D. Francisco de Quevedo. $2^{\mathrm{a}}$ ed. revisada. Madrid: Gredos.

BÉDIER, Joseph (1982). Les fabliaux. París: Champion.

Bello, Francesco (1926). Il Mambriano: libro d'arme e d'amore. Giuseppe Rua (ed.). Turín: UTET.

Bertoni, Giulio (1929). «Il Cieco da Ferrara e altri improvvisatori alla corte degli Este». Giornale storico della letteratura italiana, 94, pp. 271-278.

BogGs, Ralph S. (1930). Index of Spanish Folktales. Chicago: University of Chicago.

Bourland, Caroline B. (1905). «Boccaccio and The Decameron in Castilian and Catalan literature». Revue Hispanique, 12, pp. 1-232.

CARAPEZza, Sandra (2011). Novelle e novellieri. Forme della narrazione breve nel Cinquecento. Milán: LED Edizioni Universitarie.

Castiglione, Baldessar (1960). Il Cortegiano. Giulio Preti (ed.). Turín: Einaudi.

CAstro, Francisco de (1742). Libro nuevo de entremeses intitulado Festejo cómico, compuesto por Francisco de Castro. Tomo I. Y libro nuevo de entremeses intitulado Chistes del gusto, de varios ingenios. Madrid: Gabriel del Barrio.

Cervantes, Miguel de (2003). Novelas ejemplares. Harry Sieber (ed.). Madrid: Cátedra.

Сімеgotto, Cesare (1892). Studi e ricerche sul 'Mambriano' di Francesco Bello, il Cieco da Ferrara. Padova / Verona: Fratelli Drucker.

Everson, Jane E. (1980). Francesco Cieco da Ferrara: His Life and Works with a Special Study of 'Il Mambriano'. Oxford: University Press.

LASPÉRAS, Jean-Michel (1987). La nouvelle en Espagne au Siècle d'Or. Montpellier: Université de Montpellier.

Malespini, Celio (1609). Ducento novelle. Venecia: Al Segno dell'Italia.

MARCHESI, Giambattista (1897). Per la storia della novella italiana nel XVII secolo. Roma: Loescher.

Molina, Tirso de (1994). Cigarrales de Toledo. María del Pilar Palomo e Isabel Prieto (eds.). Madrid: Turner.

RajnA, Pio (1878). «Una versione in ottava rima del Libro dei Sette Savi». Romania, 7, pp. 22-51; 369-406.

RuA, Giuseppe (1888). Le novelle del 'Mambriano' del Cieco da Ferrara. Turín: Loescher.

SAltinI, Guglielmo E. (1894). «Di Celio Malespini, ultimo novelliere italiano in prosa del secolo XVI». Archivio Storico Italiano, 13, pp. 35-80. 


\section{DE LA NOVELLA AL ENTREMÉS PASANDO POR LA NOVELA CORTA: REESCRITURAS DEL CUENTO LA GARA DELLE TRE MOGLI DEL CieCo di FerRara}

RESUMEN : Con el presente trabajo me propongo analizar las diferentes fases de transmisión del cuento La gara delle tre mogli incluido en el poema caballeresco Mambriano de Francesco, apodado el 'Cieco di Ferrara'. A través de una novella del XvII de Orazio Celio Malespini, que primeramente reelabora el texto, se ahondará en la resemantización del mismo en la literatura española barroca: primero en una novela corta de los Cigarrales de Toledo de Tirso de Molina y, sucesivamente, en el entremés La burla de la sortija de Francisco de Castro.

Palabras Clave: Novella, Novela Corta, Entremés, Trasmisión textual, Resemantización.

\section{From nOVella to ENTREMÉS VIA SHORT NoVELS: ReWRItING the STORY of LA GaRA DELle tre MOgLi $B Y$ CIECO DI FERRARA}

AвSTRACT: This work aims to study the different phases of transmission of La gara delle tre mogli, a short story included into the chivalry poem Mambriano by Francesco, labelled the 'Cieco di Ferrara'. Beginning from a XVII century novella of Orazio Celio Malespini who firstly rewrote the text, I will deep in the resemantization of the story into the Spanish Baroque literature by analyzing a short novel of Tirso de Molina's Cigarrales de Toledo and, subsequently, the entremés La burla de la sortija by Francisco de Castro.

Keywords: Novella, Short Novel, Entremés, Textual Transmission, Resemantization. 
Evangelina Rodríguez Cuadros (Universitat de València)

Novela cortesana, novela barroca, novela corta: de la incertidumbre al canon .9

Mita Valvassori (Universidad de Los Lagos)

El modelo narrativo del Decamerón en la Edad de Oro: una vieja historia .21

Antonio Gargano (Università degli Studi di Napoli Federico II)

«Difficile est proprie communia dicere»: el género de la novella entre

Boccaccio y Cervantes

Guillermo Carrascón (Università degli Studi di Torino)

Apuntes para un estudio de la presencia de Bandello en la

novela corta del siglo XVII

Leonardo Coppola (Università degli Studi «G. d'Annunzio» di Chieti-Pescara)

La proyección de Straparola en la novela española del Siglo de Oro desde una perspectiva editorial

Mireia Aldomì García

Didactismo, género literario y lector en Giraldi Cinzio.

María Jesús Zamora (Universidad Autónoma de Madrid)

«...En tiempo menos discreto que el de agora, aunque de hombres más sabios, se

Ilamaban a las novelas cuentos». La novela corta y el cuento en el Siglo de Oro.....109

Marcial Rubio (Università degli Studi «G. d'Annunzio» di Chieti-Pescara)

La contribución de Cervantes a la novela barroca: la ejemplaridad. .125

PIERRe Darnis (Université Bordeaux Montaigne)

La fuerza de la sangre, La ilustre fregona $y$ Las dos doncellas: ¿tres tipos

folclóricos?

María Soledad ArRedondo (Universidad Complutense de Madrid)

De La gitanilla $a$ La sabia Flora malsabidilla. El género, el personaje

y el matrimonio

Antonella Gallo (Università degli Studi di Verona)

Fabulaciones en equívocos burlescos: la Chrónica del monstro imaginado (1615)

de Alonso de Ledesma y novela corta barroca

David GonZález Ramírez (Universidad de Málaga)

El filósofo del aldea (1625) de Baltasar Mateo Velázquez: recepción textual

e hipótesis autorial.

Jonathan BRAdBury (University of Exeter)

La narrativa breve en la miscelánea del siglo XVII 
Cristina Castillo Martínez (Universidad de Jaén)

«La fuente del desengaño»: de las Noches de invierno de Eslava a la Tercera

Diana de Tejeda.

María Zerari (Université Paris-Sorbonne, CLEA)

Furor in fabula: La cruel aragonesa de Castillo Solórzano (o de la dama monstruo).. 241

Giulia Giorgi (Università degli Studi di Ferrara)

Alonso de Castillo Solórzano reescritor de sí mismo: algunas notas sobre los

Escarmientos de amor moralizados y el Lisardo enamorado .257

Angela Fabris (Alpen-Adria-Universität Klagenfurt)

El diálogo con el público y los espacios reales y de maravilla en

Casos prodigiosos y cueva encantada de Juan de Piña .267

María Rocío LePe García (IES San Sebastián, Huelva)

La traducción inglesa de Hipólito y Aminta: una adaptación

con fines comerciales 281

Andrea Bresadola (Università degli Studi di Udine)

La novela española en la Italia del siglo XVII: el caso de Il Feniso

de Francisco de Quintana

José Teruel (Universidad Autónoma de Madrid)

El triunfo del Desengaño. Marco y desengaño postrero de la Parte segunda

del Sarao y entretenimiento honesto, de María de Zayas

Nieves Romero-Díaz (Mount Holyoke College)

Lecturas alternativas en la Novela del fin bueno en mal principio

de doña Ana Francisca Abarca de Bolea.

Shifra Armon (University of Florida)

Compromiso y distanciamiento en La Venus de Ferrara

de Mariana de Carvajal Saavedra

Mechthild Albert (Rheinische Friedrich-Wilhelms-Universität Bonn)

Las "noches": un subgénero novelístico en perspectiva comparada.... .365

Fernando Copello Jouanchin (Université du Maine, Le Mans)

El mueble en la novela corta del Siglo de Oro: algunas reflexiones

en torno a la cama

Ilaria Resta (Università del Salento):

De la novella al entremés pasando por la novela corta: reescrituras del cuento

La gara delle tre mogli del Cieco di Ferrara. 


\section{EDAD DE ORO}

Revista de Filología Hispánica XXXIII

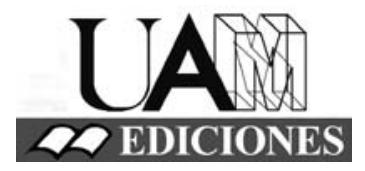




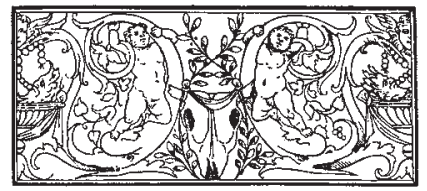

\section{Edad de Oro. Revista de Filología Hispánica}

ISSN: 0212-0429

Dirección:

Teodosio Fernández

Secretaría y edición:

José Ramón Trujillo

Coordinador del volumen XXXIII:

Rafael Bonilla Cerezo

Comité científico internacional:

Carlos Alvar (Univ. de Ginebra)

Ignacio Arellano (Univ. de Navarra)

Javier Blasco (Univ. de Valladolid)

Alberto Blecua (UAB)

Jean Canavaggio (Univ. de París X)

Laura Dolfi (Univ. de Turín)

Aurora Egido (Univ. de Zaragoza)

Víctor García de la Concha (RAE)

Luciano García Lorenzo (CSIC)

Joaquín González Cuenca (Univ. de Castilla-

La Mancha)

Agustín de La Granja (Univ. de Granada)

Begoña López Bueno (Univ. de Sevilla)

Michel Moner (Univ. de Toulouse III)

Joan Oleza (Univ. de Valencia)

Alfonso Rey (Univ. de Santiago)

Lina Rodríguez Cacho (Univ. de Salamanca)

Leonardo Romero Tobar (Univ. de Zaragoza)

Aldo Ruffinatto (Univ. de Turín)

Lía Schwartz (City University of New York)
Redacción y admisión de originales:

Teodosio Fernández

Edad de Oro

Departamento de Filología Española

Universidad Autónoma de Madrid

28049 Madrid (España)

Tfno.: +0034 914974090

correo: teodosio.fernandez@uam.es

Distribución, suscripción y venta:

Servicio de Publicaciones de la UAM

Universidad Autónoma de Madrid

28049 Madrid (España)

Intercambio de publicaciones:

Biblioteca de la Facultad de Filosofía y

Letras (UAM)

Universidad Autónoma de Madrid

28049 Madrid (España)

Han colaborado en este volumen:

Departamento de Filología Española (UAM)

Facultad de Filosofía y Letras (UAM)

Proyecto I+D FFI2013-41264-P La novela

corta del siglo XVII: estudio y edición (y II)

Edad de Oro se recoge en las siguientes bases de datos: SCOPUS, MLA Database, HLAS, Latindex, PIO-Periodical Content Index, ISOC, Dialnet, MIAR, ERIH, DICE, Sumaris CBUC, Ulrich's. Se encuentra evaluada en CIRC: A; INRECH: primer cuartil, posición 6 de 50; MIAR difusión ICDS live: 9.977; SCImago Journal \& Country Rank: H Index 2, SJR 0,101, Q4; RESH índice de impacto: 0.162; ERIH: A INT1; Carhus Plus+: B. 